\title{
Una Misionología española de sabor Agustiniano
}

En España comenzaron también muy pronto a preocupar los problemas misionales, y su enfoque seria particularmente teológico y paulino-agustiniano, queriendo buscar una justificación y motivación suficiente de la actividad misionera de la Iglesia, en la concepción paulina de la Iglesia como Cuerpo místico de Cristo, explicada de un modo típicamente misional por San Agustín. La primera exposición se haría en Diciembre del 1920 por medio de una pastoral del Arzobispo de Burgos, Mons. Benlloch, debida, en su inspiración, al jesuita $P$. José Zameza. Bien es verdad que esta explicación misional no halló gran eco fuera de las fronteras de España en aquellos primeros años, y que ha sido ignorada por los misionólogos modernos que han analizado las diversas corrientes misionológicas de nuestros tiempos. Así Seumois, en su estudio sobre el tema, ni siquiera la cita, en un estudio que es ya del año $1947^{1}$.

\section{La Carta Pastoral de Benlloch}

Con fecha 30 de Abril de 1919 escribía Benedicto XV al Arzobispo de Burgos, Mons. Juan Benlloch, encargándole la restauración o remozamiento del Seminario Nacional para Misiones Extranjeras, radicado en Burgos, y espoleando al mismo tiempo el celo misionero del Clero y del pueblo español. En esa carta le decía entre otras cosas: "Qua in re profecto non decet Hispaniam, cuius praeclara sunt in christiano apostolatu promerita, sic sui oblivisci ut cuiquam cedere videatur": "No hay duda que no es nada decoroso el que España, cuyos pasados servicios apostólicos fueron de tanto relieve, olvidada ahora de sí, se deje vencer por ningún otro pueblo" 2 .

1. "Vers une définition de la activité missionaire": Neue Zeitsschrift für Missionswissenschaft (1947) 161-178; 254-261; (1948) 1-16.

2. Véase citada esta carta, en latín primero y luego en español, en la misma Carta Pastoral, pp. 235-236 y 237-238. 
Mons. Juan Benlloch habia nacido en Valencia el 29 de Diciembre de 1864; allí mismo había hecho sus estudios sacerdotales. Fue ordenado sacerdote el 25 de Febrero de 1888, y elevado al Episcopado en San Francisco el Grande, de Madrid, el 2 de Febrero de 1902.

El 21 de Noviembre de 1918 había sido nombrado Arzobispo de Burgos, y en el Consistorio del 7 de Marzo de 1921 sería creado Cardenal, en razón precisamente de los méritos contraídos por la citada Carta Pastoral. Entre los cargos desempeñados anteriormente, hemos de recordar los siguientes: Profesor del Seminario de Valencia de 1888 a 1899, Vicario General de Segovia en 1899, Dignidad de Chantre y Vicario Capitular de la misma Sede en 1900, Obispo titular de Hermópolis y Administrador Apostólico de Solsona en 1901, Obispo de Urgel, y Príncipe Soberano de Andorra de 1906 a 1919. Falleció el 14 de Febrero de $1926^{3}$.

Ahora en el 1919 Benedicto XV le dirigía esa carta a que hemos aludido. La ocasión era oportuna, como recordaba el mismo Pontifice en la misma carta: La reciente conflagración mundial, de la que por providencia divina se había liberado España, había reducido al mínimo el número de pregoneros del Evangelio; y era menester acudir nuevamente a aquella rica cantera, que tan magnificos sillares había proporcionado de tantas iglesias indigenas en América.

Ciertamente, que también en España había decaído el espíritu misional, como había decaído en general todo a lo largo del siglo XIX. Por fortuna, desde unos años atrás se venía notando un acusado resurgimiento, que en España quedó polarizado en sus principios en torno a dos grandes nombres: Hilarión Gil y José Zameza, ambos Jesuitas. El P. Hilarión Gil puede ser tenido como el gran promotor y restaurador del espíritu misionero moderno en España. El comenzó a infiltrar este espíritu misional desde el Escolasticado jesuítico de Oña, provincia de Burgos, donde era Profesor de Historia de la Iglesia y de Patrología, tanto en aquellos estudiantes, entre los que destacó muy pronto el P. Zameza (del que daremos más adelante más amplios datos biográficos), como entre el pueblo en general por sus charlas y conferencias, y artículos misionales en diversas revistas, sobre todo en Razón y Fe. El año 1919 dejó sus clases de Oña al propio P. Zameza, y marchó a Madrid,

3. Sobre su labor misional cf. J. ZAMEZA, "Las Misiones de Luto": El Siglo de las Misiones (Abril, 1926) 121-126. El Cardenal Benlloch fue el primer Presidente de la Unión Misional del Clero en España, y restauró con nueva vitalidad el ya existente, pero mortecino, Seminario para Misiones Extranjeras, de Burgos. 
destinado por los Superiores como Director de la citada Revista. Moriría en Oña, a donde había regresado a explicar Historia Eclesiástica unos años antes, el 1 de octubre de 1928, cuando le faltaban 20 días para cumplir los 55 años.

En el 1914 había fundado la Revista misionera El Siglo de las Misiones, coincidiendo con las primeras expediciones de los Jesuitas españoles a las Misiones de China. Habian marchado en el 1913 los primeros jesuitas de Castilla, para, ayudar a los jesuitas franceses en su gran misión del Kiang-Nan, y más concretamente en la provincia civil de An-hwei. En el 1922 se erigiría en este territorio el Vicariato de Wuhu, que más tarde, en el 1929, daría lugar a tres Vicariatos: Pengpu, Anking y Wuhu, encomendados respectivamente a jesuitas italianos, y a españoles de León y Castilla. Habia luego dado a conocer en conferencias y revistas la importancia y el alcance del problema misional ${ }^{4}$, y hacía vislumbrar ya los primeros atisbos de una Misionología Española ${ }^{5}$.

$\mathrm{Su}$ espiritu y su herencia lo recogía muy pronto otro jesuita joven, dinámico, emprendedor, pensador profundo, original en sus ideas $y$ concepciones, aunque le faltara, por otro lado, un tacto de sistematizador en esos enfoques e ideas. Nos referimos al P. José Zameza, que entonces mismo finalizaba sus estudios, y habría de ser destinado, en Oña, a la explicación de la Teología Patrística, y tomaría muy pronto la dirección de la Revista, El Siglo de las Misiones. En sus estudios e investigaciones patrísticas quedó pronto prendado del espíritu católico, ecuménico, universal, misional de dos de las más grandes lumbreras del Cristianismo, San Pablo y San Agustín, llamado aquél el Apóstol de los Gentiles, y éste el Padre y Doctor de la Gracia. Y precisamente en la conexión de estos dos puntos: gentiles y gracia, está el problema misional; en ellos habia de apoyar Zameza su Misionología propia, que podemos decir hoy, es la Misionología propia de una auténtica escuela española.

Tuvo ocasión de exponer al público sus concepciones misionales precisamente en la Carta Pastoral, que el día de San Francisco Javier de 1920, publicaba en Burgos su Arzobispo Mons. Benlloch. Hoy ya no es un secreto para nadie que aquella Pastoral, magnifica por su concepción misional, se debió al genio misionero y devoto

4. En la Revista Razón y Fe, tomos 25-26, del año 1909 , había ya publicado unos cuantos artículos sobre las misiones católicas entre infieles.

5. Hemos estudiado ya más a fondo este tema en nuestro libro Una $M i$ sionología Española (Bilbao, 1958) 172, y es la que reproducimos en parte-en estas páginas. 
del P. Zameza; a quien acudió el que había de ser futuro Cardenal: ${ }^{6}$. Como ya hemos recordado antes, se esboza en ella una auténtica Misionología española, cuyas características se apoyan en la concepción teológica del Cuerpo Místico, enseñada por San Pablo, y comentada por San Agustin.

España, que se había distinguido en su apostolado histórico misionero, iba a adelantarse también a otras muchas naciones en el campo de la Misionología científica, que en estos años estaba dando sus primeros pasos y balbuceos. Firmada aquella Pastoral por el Arzobispo de Burgos en Diciembre del 1920, aunque era posterior a las ideas ya expuestas en Alemania por el Dr. Schmidlin, se adelantaba unos años a las teorías que habían de exponer en Bélgica, Lange y Charles en 1924 y 1926 respectivamente; y luego en Francia diversos teólogos y misionólogos a partir del 1932. Veamos el juicio que le mereció entonces al General de los Jesuitas, P. Wlodimiro Ledochowski, que escribía así, felicitando al Arzobispo:

"Más que una simple Carta, es un completo y profundo tratado teológico del espíritu misionero de la Iglesia Católica, en que se juntan un conocimiento claro de su vida íntima, necesariamente expansiva, y una exposición exacta de su desarrollo histórico, animado todo, con una unción apostólica y una universalidad y grandiosidad de miras, que no podría menos de despertar en el clero y en el pueblo de su amada Archidiócesis y de toda España, eminentemente católica, el entusiasmo generoso por la obra que el Romano Pontífice ha confiado al celo Pastoral de S.E.I. Esta carta será, indudablemente, un monumento de gloria para S.E.I., y para la Archiđiócesis de Burgos, y una fuente en donde han de beber el genuino espíritu apostólico de la Iglesia cuantos tengan la dicha de ser llamados a cooperar a la sublime misión de la evangelización de los infieles" ".

Apunta el P. Ledochowski que la Pastoral constituye un completo y profundo tratado teológico de Misiones. Así es, en realidad, aunque dado el carácter del documento, no pueda esperarse una precisa sistematización escolástica, sino más bien una amplia perspectiva de horizontes positivos, cualidad que estaba también más a tono con la mentalidad del P. Zameza. Pero si no un tratado teológico misional preciso, si encontramos los elementos, desarrollados

6. Lo fue por Benedicto XIV en el Consistorio del 7 de marzo de 1921 , tres meses, por lo tanto, después de la publicación de esta Carta Pastoral.

7. Cf. El Siglo de las Misiones (1921) 186. 
después más ampliamente por el mismo Zameza, de esta característica escuela misional.

Notemos bien el año. La Pastoral se publicó en Diciembre de 1920, época en que, ciertamente, ya estaban acuciados por estos problemas teológico-misionales los alemanes, tanto católicos como protestantes, pero en la que aún no habian despertado estas mismas inquietules en otras naciones, como Bélgica y Francia en con. creto, que había de aparecer algunos años más tarde. Hasta hubo autores, españoles, que dejando a un lado esta propia concepción española por ignorancia, por olvido, o por menos estima, se apresuraron a exponer y comentar las teorias extranjeras. Hoy mismo, los Misionólogos modernos, cuando expresamente tratan de exponer y explicar las diversas teorías teológicas del problema misional, se olvidan también de lo mismo, ¿por olvido?, ¿por menos estima?, ¿por ignorancia? No lo sabemos. Es posible que todos estos factores se conjuguen a una, para producir idéntico producto: la ausencia española, como tal, dentro de la Teología misional ${ }^{8}$. Pero ahí queda y quedará para el futuro esa Pastoral magnífica, publicada en el 1920, eje y clave de la escuela teológico-misional española, debida al Cardenal Juan Benlloch y al jesuita P. José Zameza.

La citada Pastoral que lleva como título, Las Misiones Extranjeras. Invitación pontificia a Burgos ${ }^{9}$, comprende tres partes, de ellas la más importante, desde nuestro punto de vista, es la primera, rotulada Teología y Misiones, en la que expone embrionariamente nuestra Dogmática Misional; la segunda es más bien una exposición histórica tanto doctrinal como práctica de la Iglesia Mi-

8. Hemos recordado antes la postura de André Seumois en su estudio Vers une définition de l'activité missionaire, publicado en 1947. De entonces acá no se ha adelantado gran cosa. Un ejemplo: en 1956 publicaba el P. Eduardo Loffeld, de la Congregación del Espíritu Santo, una gran obra de 416 bien nutridas páginas, y cargada además de eruditas notas, titulada Le Problème cardinal de la Missiologie et des Missions Catholiques. Editions Spiritus, en Rhenen de Holanda. Parece desconocer en esta obra las ideas misionales de España. No cita ni una sola vez al Cardenal Benlloch, y al P. Zameza sólo una, en la p. 268, pero no directamente, sino al citar un artículo del P. Olegario Domínguez. El P. Loffeld no conocía, pues, las obras del P. Zameza, aunque sí sus ideas, expuestas en otros autores. Algo parecido podría decirse de otra obra posterior, y de otro misionólogo de talla, el benedictino P. Tomás Ohm, en su libro Machet zu Jüngern alle Völker. Theorie der Mission (Freiburg in Breisgau 1962) 927; la obra ha sido recientemente traducida al francés. Basten estos dos ejemplos, por no citar algunos más. Hemos de reconocer, sin embargo, que algunos autores posteriores acuden a veces a la teoría española para explicar puntos determinados de la actividad misional.

9. Publicada en Burgos el año 1920, en la Tipografía de Polo; comprende 239 páginas. 
sionera; y la tercera expone los puntos de tipo pastoral que hacen ver su necesidad y su urgencia.

\section{Exposición doctrinal}

Es natural que la teoria no sea, en su exposición, perfecta. Aparecerán primero los primeros chispazos, las primeras ideas, fecundas en contenido y consecuencias, que irán perfilándose después con nuevas aportaciones de los mismos autores, o de otros, a quienes agraden esas ideas. Le había pasado lo mismo a Schmidlin en Alemania, y les pasaría a Charles en Bélgica, y más tarde a los primeros misionólogos en Francia.

¿En qué consiste, pues, la esencia de esta escuela española? El propio $P$. Zameza haría un análisis de la Pastoral en un artículo publicado el año 1951, El Cuerpo Místico de Cristo en la Dogmática Misionera en España desde el Maximum Illud, publicado en la $\mathrm{Re}-$ vista Misiones Extranjeras ${ }^{10}$ : Este mismo artículo salió reproducido después en el tomo-homenaje con que algunos misionólogos de todo el mundo obsequiaron al P. Dindinger OMI, Bibliotecario de la Propaganda Fide con ocasión de su 70 aniversario ${ }^{11}$ :

En toda concepción misional, decía el P. Zameza, han de tenerse en cuenta, y conjugarse, estos dos elementos tan desarrollados por San Pablo: Paganismo e Iglesia; las mutuas relaciones entre ambos es lo que constituye precisamente la teología misional, la Iglesia misionera ${ }^{12}$. Es un paralelismo mundial en el que el Paganismo representa el elemento negativo, ampliamente descrito y determinado por San Pablo en sus cartas, sobre todo en la escrita a los Romanos, y en el que la gracia, y consecuentemente la Iglesia, representa el elemento positivo, centrado en esa institución divina, como Cuerpo Místico de Cristo. El cuadro que del Paganismo pinta el Apóstol es desolador; todos están alejados de la vida de Dios: alienati a vita Dei ${ }^{13}$ que es la gracia, que habrán de conseguir precisamente por medio de la Redención en la Iglesia de Cristo, que es la única que puede aportar convenientemente la regeneración de esa sociedad empecatada y perdida.

La transformación nos vendrá por Cristo, Sol de justicia, que iluminará sus almas: Eratis enim aliquando tenebrae, nüc autem

10. J. ZAMEZA, "El Cuerpo Místico de Cristo en la Dogmática Misionera en España desde el "Maximum Illud": Misiones extranjeras (1951) 34-50.

11. En Missionwissenschatfliche Studien (1951) 54-74.

12. Cf. Carta Pastoral, 24-26.

13. Rom 1-2. 
Iux in Domino: Antes érais obscuridad, tinieblas; ahora sois luz en Cristo $^{14}$.

Pero donde entra Jesús y entra su gracia es imposible prescindir de su Iglesia. El Totus Christus, el completo, o sea, el conjunto de Cristo como cabeza, y de la Iglesia como cuerpo, doctrina clave en la teología paulina, y pensamiento obsesionante del Doctor de la Gracia, San Agustín, y con el que se encuentra a cada paso el lector en sus exposiciones bíblicas, es como la resultante y el remate natural de esos dos factores, Cristo y la gracia, en la actuación del gran Sacramentum pietatis ${ }^{15}$, de que nos habla San Pablo: ${ }^{16}$.

Quedan expuestos los dos elementos: el negativo, paganismo, y el positivo, gracia e Iglesia. ¿Dónde está, y cómo se verifica esa unión entre ambos, qué es lo que constituye el problema misional? Está en la transformación del primero hasta convertirse en el segundo; y esta transformación, esta unión asimiladora y transformante no encuentra una concepción más atinada, y una realidad más misteriosa, que la teoría doctrinal paulina explanada por San Agustín, del Cuerpo Místico de Cristo. Este Cuerpo, que se había de nutrir expresamente de la gentilidad, del paganismo, y que había de centrar en esa operación generadora y asimilante toda su razón de ser y de vivir ${ }^{1 r}$.

Tenemos aquí el primer estadio misional: Ecclesia ex gentibus; primera transformación, primera transfusión de los tesoros más preciados del Corazón de Cristo a los pueblos antes estigmatizados y empecatados, del Paganismo. Ser un cuerpo místico con El, formar un todo completo con El, participar de la misma vida de El, y de las promesas antiguas, por $\mathrm{El}^{18}$. Cristo llama San Agustín, con santa y teológica osadía, a un hombre en gracia; y ya antes que él, Tertuliano con vista panorámica de toda la Iglesia, extendida por todo el mundo, había escrito en frase no menos admirable: Ecclesia vero Christus: La Iglesia es el mismo Cristo.

Será inexplicable a la razón, pero esa transformación es un hecho: Ecclesia ex gentibus. Aquí está ese Mysterium Christi, ese Misterio de Cristo, por el que los gentiles son llamados a ser miembros de un mismo cuerpo, y participantes de la promesa divina en Jesu-

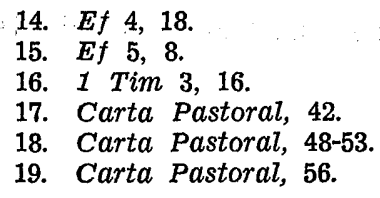

19. Carta Pastoral, 56. 
cristo mediante el Evangelio. Dificilmente se puede imaginar una concepción, aun en el orden estético, más avasalladora, que la encerrada en esas breves palabras de San Pablo: Mysterium Christi. Es la labor divinamente sublime de la Iglesia Misionera: transformar la gentilidad en Cristo: Ecclesia ex gentibus ${ }^{20}$.

Tenemos el hecho de la tansformación, de la regeneración en Cristo. ¿Cómo se verifica en concreto esa transformación? La fórmula Ecclesia gentium o Ecclesia ex gentibus, tan agustiniana, es uno de sus puntos básicos, de ricas consecuencias, Ese Ex gentibus significa Iglesia hecha de lo que había sido gentilidad, para, transformada por la $\mathrm{Fe}$ en el Cristianismo, seguir actuando en convertir por la misma $\mathrm{Fe}$ el resto del mundo infiel, haciéndolo la misma Iglesia Esposa de Cristo. En esta latísima y sobrehumana transformación del Paganismo en Iglesia y en Cristo, entran tres factores teológico-misionales: La Cristianización (en cuanto distinta de la justificación), la Fe, la Iglesia Misionera ${ }^{21}$.

Cristianización, o sea, esa fuerza maravillosa que opera la transformación del Paganismo en Cristianismo, cristalizada en aquella frase de San Agustín: Vis convertens in se materiam. VIS, una fuerza, el elemento activo asimilante, transformador, de fuerza infinita y Materia, el elemento pasivo, material, inerte, sin vida, que ha de transformarse; el mundo que aún no es parte de Cristo, es decir, los Gentiles. Convertens: se trata de una conversión que supone una pérdida real, a la que sucede una adquisición así mismo real, Todo ello queda hermosamente englobado en la frase agustiniana, que, como suya, parece jugar con los términos, y está llena de contenido: O Ecclesia... Occide quod sunt, et fac quod es: Mata lo que son, esto es paganismo, infidelidad, idolatria; y haz de ellos lo que tú eres, es decir, Cuerpo de Cristo.

Conversión maravillosa que se ha de hacer por medio de esa fuerza, maravillosa también, divino, que tiene este Cuerpo Místico vivo, y de Cristo, fuerza vital y transformadora, y transformación vital asimiladora, con todos los caracteres vitales del crecimiento y de la nutrición.

Este es el símil propio de nuestra teoria; insistir en la metáfora viva y real, llena de sentido, que compara la labor de crecimiento y asimilación de los paganos por parte de la Iglesia, como lo hacen con los alimentos los cuerpos vivos; es lo que caracteriza a esta teo-

20. Carta Pastoral, 58-59.

21. Carta Pastoral, 62-64. 
ría, que ve en ello una explicación adecuada del problema misional. En ello, no hace sino seguir los pasos y la doctrina del Obispo de Hipona, cuando escribía, explicando la visión de San Pedro en Joppe ${ }^{22}$. "Prefiguraba el Señor a la Iglesia, que había de devorar a todas las gentes y convertirlas en su cuerpo" ${ }^{23}$.

Conversión y cristianización, que se opera mediante una fuerza orgánica de asimilación, completada por una operación vital doble: exterior la una, que consiste en la predicación y atracción de los pueblos al torrente circulatorio de su vitalidad; e interior la otra, o sea la conversión en sí, o intususcepción de elementos hasta entonces extraños a ella, pero que constituirían en adelante parte integrante del mismo organismo transformador ${ }^{24}$.

Dos leyes físicas de los seres vivos: la elasticidad adaptativa y el crecimiento progresivo, dotadas ambas de unas propiedades, realizables también en la Iglesia de Jesucristo. Por la primera queda asegurada su existencia y su unidad en medio de la mayor variedad y discrepancia de los pueblos, conforme a los principios de la sana adaptación tan patrocinada en nuestros tiempos, aplicada al apostolado moderno. $Y$ por la segunda, su vitalidad misionera, pues su crecimiento y duración son indefinidas mientras haya pueblos que incorporar. Lo lleva embebido en su esencia misma; por su función esencial de predicar el Evangelio a toda criatura, ha quedado revestida esencialmente de esa ley que llamamos Catolicidad, o sea la universalización de la Iglesia, formulada e intimada por el mismo Jesucristo. Esta ley de la Catolicidad lleva incluida en sí la labor de las Misiones ${ }^{25}$.

$L a F e$. Es el germen vital obrador de estas transformaciones maravillosas: ella constituye el principio de asimilación de la Iglesia: "Ella es la que en esta fe... fructifica, y crece hasta el mundo universo", que comentaba San Agustín ${ }^{26}$, y que San León Magno definía Propago fidei, refiriéndose a la extensión del Catolicismo ${ }^{27}$. Lo había proclamado antes así el mismo Cristo: quien creyere (entiéndase el Evangelio predicado), y se bautizare, se salvará: y quién no creyere será condenado. Una fe, pero no sola, sino sella-

\footnotetext{
22. Hech 10, 11-16.

23. Enarrationes in Ps. 30.

24. Carta Pastoral, 67.

25. Carta Pastoral, 68.

26. Serm. 214, 4.

27. Carta Pastoral, 71.
} 
da con su única marca oficial ante Dios y la Iglesia, que es el Bautismo: El que creyere $y$ se bautizare ${ }^{28}$.

\section{La Iglesia Misionera}

Es la que, como madre espiritual, ha de hacer germinar este germen vital de inserción e incorporación a Cristo, como bellamente lo expresa San Agustín en aquellas palabras: Ecce uterus Matris Ecclesiae, ecce ut te pariat atque in lucem fidei producat ${ }^{29}$. Este es el seno de la madre Iglesia, para que te dé a luz; y te lleve a la luz de $\mathrm{la} \mathrm{fe}^{30}$.

A la luz de estas ideas, es como tiene explicación plena, y comprensión, la expresión dulcísima con que la designamos: Nuestra Santa Madre la Iglesia, pues ella viene a hacer en el orden sobrenatural, lo que en el natural hace la propia madre: explicación obvia y natural que produce la concepción española de las Misiones. Aquí se basa también la explicación del axioma Extra Ecclesiam nulla salus, de que fuera de la Iglesia no hay salvación, como no hay vida sin la madre. No hemos de entrar en la explicación teológica de cómo pueden y suelen salvarse muchos infieles, sin que se les reconozca en el foro externo como miembros de la Iglesia católica jerárquícamente organizada y visible; lo inconcluso es que todos los que se salvan, sólo consiguen la bienaventuranza, por la Iglesia, y en la Iglesia, como sólo pueden conseguirla en Cristo y por Cristo.

No puede tener por padre a Dios quien no tiene a la Iglesia por madre, exclamaba en su época San Cipriano ${ }^{31}$, indicando con ello la necesidad de pertenecer a la Iglesia en razón de su maternidad y consiguiente filiación; expresión que es la que mejor sintetiza ese doble pensamiento católico de aquella época.

Hemos resumido en una página toda la fuerza teológica de la concepción española con respecto a la actividad misional, a la luz de los grandes y potentes focos de la Teología Católica, San Pablo y San Agustín, que lo entrañan en su concepción y símil biológico de la Iglesia como Cuerpo Místico de Cristo. Lo demás no son ya más consecuencias, en las que insisten más o menos, las otras es-

\footnotetext{
28. $M C 16,16$.

29. Serm. 216, 5 .

30. Carta Pastoral, 74-76.

31. De unitate Ecclesiae, V: PL 4, 502.
} 
cuelas o explicaciones extranjeras. Precisamente para llegar a esta transformación del Paganismo en Cristo, hubo de transmitir el Señor a los Apóstoles y a su Iglesia su propia misión. Como me envió el Padre a Mí, así os envío Yo a vosotros ${ }^{32}$ para que predicasen la buena nueva e infundiesen la fe que injerta e incorpora en Cristo. ¿Y cómo predicarán si no son enviados?, comenta San Pablo; tienen que ser enviados; es la Iglesia misionera ${ }^{33}$.

Aún hay otro elemento, que es necesario, para comprender esta teoría misional. San Pablo y San Agustín hablan de esta Iglesia como de Cuerpo Místico de Cristo, un Cuerpo místico, sí, es decir, misterioso; pero no por eso menos vivo y real. Pero el cuerpo no existe solo; si así fuera, no tendríamos más que un cadáver. El cuerpo vivo y real necesita un alma que lo vivifique y dé vitalidad a sus potencias o fuerzas de actuación. $Y$ esta alma también la tiene necesariamente este Cuerpo Místico de Cristo. ¿Cuál es esa alma? Esa alma es el Espiritu Santo ${ }^{34}$. Hermosamente lo expresaba con esta frase San Agustín: Lo que es el alma para el cuerpo del hombre, eso es el Espíritu Santo para el Cuerpo de Cristo, que es la Iglesia ${ }^{35}$.

El hace que crezcan y se desarrollen sus miembros. El es la luz y la dirección en la Jerarquía, como fuerza de asimilación en las Misiones. El produce, modera, dirige, encauza, armoniza, en admirable unidad, todas las energías de la Iglesia, tanto en sus relaciones como sus conquistas de fuera, esto es, de la Iglesia en formación, o de la Iglesia Misionera; como en sus relaciones con la perfección interior del organismo ya formado, esto es, de la Iglesia constituida; El la anima y fecunda con una virtud asimilativa y regenerativa indefinida, por la que podrá extenderse por todo el mundo, y durar hasta la consumación de los siglos.

Tal es en su conjunto la Iglesia de las Misiones; Iglesia dulcísima y maternal Esposa la llama también con relación al Espíritu Santo, en razón de su maternidad y fecundidad espiritual, en la que derramó Cristo a torrentes, todos los tesoros de su hermosura y fecundidad espiritual. Esta concepción teológica es la que debe estar en el arranque, y ser como el alma de toda ciencia de las Misiones: al menos así la concibe esta escuela española.

Porque si Cristo es siempre la única cabeza de la Iglesia ${ }^{36}$, por

32. Jn 20, 21.

33. Carta Pastoral, 78-100.

34. Carta Pastoral, 100-102.

35. Serm. 217, 6 .

36. 1 Cor $17,27$. 
el misionero es por quien crece cada día más ese su cuerpo místico; si Cristo es el único fundamento de este edificio ${ }^{37}$, por el misionero es por quien se amplía, se dilata y se eleva cada día más, dando cabida en sus aulas a todos los pueblos de la tierra; si Cristo es la única semilla de vida ${ }^{38}$, por el misionero ha de verificarse en parte esa germinación y desarrollo, hasta transformarse en el árbol frondoso de la Iglesia, que dé cabida en sus ramas a todas las aves del cielo; si Cristo es el único primogénito entre todos los hermanos ${ }^{39}$, al misionero se debe que se multiplique cada día más esa relación de fraternidad, que haga de todos los hombres verdaderos hermanos entre sí, e hijos del único Padre que está en los Cielos ${ }^{40}$.

Delicadeza y excelencia sumas las del misionero, -termina su exposición la Carta Pastoral-; en sus manos ha depositado Jesucristo lo más precioso de su amor, los intereses de su Iglesia; intereses que sólo suelen confiarse a la intimidad más grande y a la fidelidad más íntegra y probada. Tales son, la Iglesia Misionera y el Misionero ${ }^{41}$.

Qué fecunda, teológicamente, resulta en ideas misionales esta Pastoral. Evidentemente da ella los elementos precisos, abundantes e indispensables, para poder levantar una concepción maravillosa de Misionologia, científica y devota a la vez, que nos hace a todos, actores y agentes activos, en el plan universal de Cristo Redentor. Sin querer, y aun sin saberlo, estamos, como miembros que somos de este Cuerpo Místico, concurriendo activamente a la plenitud de desarrollo del Cristo total: todos somos misioneros. Falta sistematización, es verdad, conformación e impronta de escuela; no se preocupa de explicar, como hacen otros, la teoría misional enmarcada en las cuatro causas de la concepción aristotélica; no baja al terreno de la práctica, procurando dar una explicación adecuada a cada uno de los detalles de toda concepción misional: ni era ese tampoco el fin, ni el género de una exposición, como ésta, primordialmente pastoral. Pero, sin embargo, ahí están todos los elementos, abundantes, ricos, teológicos, patrísticos, apostólicos... que arrancan del mismo Cristo.

\footnotetext{
37. 1 Cor $3,11$.

38. Jn 13, 23; 15,5 .

39. Rom 17, 28; Hebr 11, 10 .

40. Carta Pastoral, 109.

41. Carta Pastoral, 110.
} 
Ulterior desarrollo del P. Zameza

El Cardenal Benlloch moría el 14 de Febrero de 1926. El P. Zameza, director entonces de El Siglo de las Misiones, recogia su herencia misionera. Ya en Junio de 1920 habia comentado en la misma revista, en un jugoso artículo, la Carta Apostólica de Su Santidad Benedicto XV (Maximum Illud) ${ }^{42}$, con ideas teológico-misionales idénticas a las que medio año más tarde habia de aparecer en la Carta Pastoral. Eran, además, ideas ampliamente comentadas en sus conferencias, conversaciones particulares, y exposiciones doctrinales, mucho antes de que en Lovaina comenzaran a apuntar los gérmenes de una nueva escuela misional con Lange y Charles, en 1924 y 1926 respectivamente.

\section{Datos biográficos del P. Zameza}

Quien quiera ver una biografía más detallada del P. Zameza, vea nuestra obrita Una Misionología Española, pp. 119-162, donde se da a conocer su biografía y su bibliografía. Aquí nos contentaremos con algunos datos resumidos. Había nacido el 11 de Enero de 1886, de un hogar cristianísimo "en el anchuroso valle vizcaíno de Munguia, de rientes perspectivas, fomentadoras de su poderosa facultad de percepción sensitiva derramada en inagotables y expresivas imágenes" ${ }^{43}$. Allí corrió su niñez alegre y sano, correteando por las praderas encantadoras del valle, escuchando el rumor del río y el parloteo de los pájaros, y empleando su tiempo infantil, y su ingenio incipiente de artista, en modelar figurillas de barro, mientras saboreaba los mejores melocotones del huerto ${ }^{44}$.

A los 12 años, ingresaba, el año 1898, en el recién fundado Seminario de Comillas, que dirigían los Padres jesuitas desde 1892, época de su fundación, en la riente costa montañesa de Santander. Cinco años después, el 3 de Septiembre de 1903, y contando 17 años de edad, iniciaba su vida religiosa en el noviciado de Loyola, cuando finalizaba su Provincialato su tío el P. Isidoro Zameza. Dos años de Noviciado en Loyola; luego otros dos de Retórica en Burgos; y tres de Filosofía en Oña. Estaba entonces en aquella casa de Profesor de Historia Eclesiástica y de Patrologia, el P. Hilarión Gil, que

42. J. ZAMEZA, "La Carta Apostólica de Su Santidad Benedicto XIV": El Siglo de las Misiones (1920) 201-207.

43. I. A. CUE, "La última página": Angeles de las Misiones (1957) 58. 171.

44. L. LOPETEGUI. "El P. José Zameza": El Siglo de las Misiones (1957) 
había de ser el animador moderno del espíritu misional en España, como ya hemos adelantado antes.

Aunque pertenecía a la Facultad de Teología, y por tanto no estaba en contacto con los filosofos, el joven Zameza, que ya sentía hervir en sus venas el fervor misionero, pidió y obtuvo una larga entrevista con él, que recordaría luego con agrado toda su vida: fue concretamente el año 1909.

Finalizados sus estudios filosóficos, marchó, en el verano de 1910, a Comillas nuevamente, ahora como profesor de estudios humanísticos, como director de una academia de griego que tenian los mismos seminaristas, y como inspector o encargado de los alumnos. Cuatro años estuvo desempeñando estos cargos en aquel seminario tan querido para él, donde había pasado otros cinco, antes de entrar en la Compañía. Ahora venía con nuevos ideales, y quería transmitir su fervor misionero también a sus encomendados.

Años más tarde, concretamente en el 1916, cuando estudiaba en Oña segundo año de Teología, él fue quien interesó a su padre, D. Vicente Zameza, para que sufragara los gastos del viaje y estipendios necesarios, para que el P. Gil fuera a Comillas a dar unas conferencias, que puede decirse fueron la semilla misional de aquella Universidad Pontificia, de donde han salido los más insignes paladines de las Misiones en el Clero secular. Era entonces alumno de teología D. Angel Sagarmínaga, tantos años Director Nacional de las Obras Misionales Pontificias en España. Ciertamente, la visita del P. Gil llenó aquellos años los ámbitos de la Universidad Pontificia, de entusiasmos misionales.

No pudo acompañarle entonces, pues se lo impedia su situación de estudiante; pero años más tarde, en 1926, siendo ya Director de El Siglo de las Misiones, pudo trasladarse en persona a su querido Seminario-Universidad, y presidió varias de sus sesiones privadas y públicas, marcándole orientaciones concretas para su actividad misional.

Al comenzar en Oña su Teología, volvió a encontrarse con el P. Hilarión Gil, que ahora sería, además, su Profesor en la cátedra en la que precisamente le habia de sustituir él mismo; y con quien contrataba y encendía de continuo su espíritu misional. Es el momento en que se orientaría definitivamente para toda su vida: desde entonces su ideal girará en torno a dos polos, no opuestos, sino complementarios en tantas ocasiones: la idea misional en sus diferentes aspectos, y el estudio patrístico sobre todo de San Agustín. Ambos polos constituirán todo el eje de su vida. Se dice que en el 
día de su ordenación sacerdotal y primera Misa, entre sus diversas peticiones al Señor, llevaba estas dos: que surgieran un Seminario de Misiones, y un plantel de Religiosas Misioneras. Ciertamente que ambas peticiones le fueron concedidas, $y$ en su desenvolvimiento había de tener gran intervención el mismo Zameza: El Seminario de Misiones Extranjeras de Burgos, origen de la famosa Carta Pastoral, y la Congregación de Religiosas de Bérriz, en cuya institución misionera tuvo tanta parte el P. Zameza.

Terminados sus estudios teológicos, le encontramos el curso 1918-1919 en Burgos, haciendo su Tercera Probación. Aún estaba en esta etapa de formación cuando llegaba al Arzobispo de Burgos la Carta de Benedicto XV. Recordemos que esa habia sido una de sus fervientes peticiones el día de su ordenación. Los tres años siguientes se le encuentra nuevamente en Oña, después de una pequeña temporada de especialización en Alemania, en Historia Eclesiástica y en Patristica Misional, esferas en que habia de sobresalir en los años de su docencia. Sucedia en esta cátedra al P. Hilarión Gil, nombrado entonces Director de Razón y Fe, en Madrid. Juntamente quedaba agregado a la plantilla de escritores de El Siglo de las Misiones. Aquí le bụscó el Sr. Arzobispo de Burgos para encargarle el estudio y bosquejo, e incluso la redacción de su magna Carta Pastoral sobre las Misiones Extranjeras. Se publicaba el 3 de Diciembre de 1920, y ese mismo año y fecha, quedaba inaugurado también el Seminario de Mișiones Extranjeras, del que sería más tarde nombrado Padre Espiritual el propio P. Zameza.

El camino definitivo quedó concretamente marcado en 1922 cuando, dejando sus clases de Historia y Patrología en Oña, se trasladaba a Burgos, nombrado Director de la Rivista pues su anterior director, $\mathbf{P}$. Víctor Elizondo, habia marchado como misionero a China. Diez años de trabajo intenso, desplegando una actividad variadísima de escritor, de conferenciante, de predicador, de asiduo colaborador en Congresos misionales, de iniciador de nuevas series de actividades dentro de la mișma Revista. Su proselitismo católico y su universalismo se contagiaban en las conversaciones privadas, en su abundante correspondencia, en sus amenas charlas, y en sus repetidas conferencias, en las que resplandecía su saber, servido por una expresión transparente y sencilla, muy peculiar suya, rica en imágenes y comparaciones, que le daban colorido, vida, amenidad y luz. Teólogo profundo, transido siempre de un lirismo, que se enlazaba a la maravilla con un conocimiento real del campo que debía labrar, y una visión clara de los objetos que perseguia, arrastraba 
suavemente, e inspiraba una gran seguridad. Por todo este conjunto de cualidades: por su caballerosidad y nobleza de corazón, por su acendrada caridad cristiana, por su trato agradable y acogedor, y por su fiel amistad, era uno de esos hombres llamados a crear clima y escuela.

Idea suya fue la publicación de los Cien proyectados fascículos Misionales, que contenían toda una programación de la Misionología teórica e histórica misional, de los que llegaron a publicarse bastantes, aunque no en toda su integridad, de los cien fascículos proyectados. La proclamación de la República Española en el 1931, la consiguiente dispersión de la Compañía de Jesús en España, y su llamada a Roma, interrumpieron esta prometedora publicación, que luego ya no se siguió. Cuando se interrumpió definitivamente iban publicados ya unos 25 estudios de divulgación críticamente documentados, que habían de encerrar en su conjunto un riquísimo arsenal de materias predicables sobre Misiones. $Y$ junto a estos fascículos otras obras de mayor envergadura y extensión, todas ellas de rico material misional ${ }^{45}$.

Otro de sus apostolados fue la Cruzada Misional de Jóvenes, que, orientada por él desde Burgos, encuadraba las juventudes de ambos sexos en los colegios e instituciones dirigidas por Religiosos y Religiosas, y que en 1925 se acercaba mucho al número total de 150.000. Esta organización juvenil misionera de tan amplios horizontes, no la había fundado él precisamente; existia ya de años atrás, desde 1914, concretamente; pero él fue quien le imprimió un ritmo más acelerado y un anhelo mạ́s ardorosamente misional.

Luego sus intervenciones en los dos grandes planes de su vida, el Seminario para Misiones extranjeras de Burgos, y la fundación, o más bien, la proyección misionera de unas Religiosas ya existentes, pero que admitieron un cambio en sus constituciones, con una proyección esencialmente misionera, las Religiosas Mercedarias de Bérriz.

En cuanto al Seminario de Misiones, ya hemos dicho que fue nombrado su director espiritual, desde el 1926. De estas relaciones

45. Véase algunos de sus títulos: El campo de las Misiones; Cristo el único Mesías Salvadior; El universalismo de la Iglesia naciente; San Pablo ante la España pagana; Poder del germen inicial evangélico; Intensidad misional de la Era de las persecuciones; Los mártires misioneros de las persecuciones; San Bonifacio Apóstol de Alemania; Alma Mater, o la Sagrada Congregación de Propaganda Fide; El Clero indígena; Las primeras Auxiliadoras de las Misiones; La Novena de la Gracia; Los grandes enemigos de las Misiones, etc. 
escribía él mismo el año 1951: "No pertenezco a vuestro Instituto, aunque siempre he sido fiel a mi primer amor desde 1919 a vuestro Seminario de Misiones Extranjeras. Dios, no sé cómo, crea a veces parentescos espirituales entre las almas. En la mía llevaba yo siempre, desde que me ordené sacerdote en 1917, vivísimos deseos de que en España hubiese un Instituto de Misioneros del Clero Secular, al estilo de los de París, Milán, Mill-Hill, etc., y el Señor sabe que fue precisamente esa una de las gracias que con más ahínco pedí el día de mi primera Misa. Yo no sabía nada, pero ya para entonces - lo supe después-, había habido en la Nunciatura de Madrid quien trabajaba en este sentido: fruto de lo cual fue tal vez la carta que Su Santidad Benedicto XV dirigió al futuro Cardenal Benlloch... Y al levantar la patena en el ofertorio de la primera Misa (era el día de san Ignacio de 1917), allí iba en forma de deseo y petición, el anhelo que tan hondo nos había metido el P. Gil en el corazón con sus sencillas clases, venero de fecundos ideales" ${ }^{46}$. Ya no nos pueden extrañar esas relaciones de amistad y "parentesco" espiritual, como él dice, con el Seminario de Misiones Extranjeras de Burgos. Cuando en el 1942 publicó su folleto sobre la conversión del mundo infiel en la concepción del Totus Christus de San Agustín, tuvo la delicadeza de dedicarlo al mismo Seminario, en la persona de su Rector, que lo era entonces. D. Emilio Rodero Reca. De ahí que luego hubiera de tener intima relación con Semanas Misionales de Burgos, de las que fue asiduo colaborador, y aún organizador.

Algo parecido puede decirse del Instituto Misionero de las Mercedarias de Bérriz, no perfilado aún concretamente en el ofertorio de aquella primera Misa, pero con el que comenzó a tener contactos ya en 1920. Acababa de iniciarse entonces el movimiento misional en el Colegio. Cuatro años más tarde pugnaba ya por tomar cauces misioneros el mismo Instituto. Como consecuencia, en el 1926 salía del Monasterio de Bérriz (de clausura papal por entonces), la primera expedición de Misioneras para la Misión de Wuhu (China) donde trabajaban jesuitas de la misma provincia religiosa del P. Zameza. En la raíz de esta transformación misionera, con la M. Margarita María Maturana y la M. María de las Nieves Urizar, se encontraba el P. José Zameza, a quien el Instituto de las Mercedarias Misioneras de Bérriz venera como Padre y bienhechor amadísimo. En 1934 fallecía, como consecuencia de una operación, la M. Maturana, y poco después publicaba el P. Zameza su biografía. La intituló Una Virgen Apóstol según las exigencias de nuestra épo-

46. La Carta está reproducida en Id (1957), núm. 97, en la portada interior. 
ca ${ }^{47}$. Desde 1930 se operó la definitiva transformación jurídica de las antiguas Religiosas Mercedarias de Bérriz, y en adelante se llamarian oficialmente Instituto de Religiosas Mercedarias Misioneras de Bérriz.

El contacto que desde los primeros años de la transformación tuvo el P. Zameza con las Mercedarias de Bérriz, se mantuvo siempre profundo y constante. Así lo reconocen las mismas Religiosas, que con ocasión de su muerte, le dedicaron un número íntegro de su Revista Angeles de las Misiones, Mayo-Junio de 1957, como le habían dedicado otro en 1932, por orden expresa de la General $M$. Maturana, cuando fue llamado a Roma para ponerse al frente de la nueva Facultad de Misionología de la Universidad Gregoriana.

Ese año 1932 se operó un pequeño, o grande cambio, según se lo considere, en su vida. Dejaba la actividad inquieta del propagandista, del conferenciante, del director de Revista, para volver a asumir el cargo reposado, estudioso, tranquilo del profesor, que juntamente con la docencia, profundiza, estudia y escribe el fruto de sus investigaciones $\mathrm{y}$ meditaciones; este nuevo período había de durar hasta el fin de su vida, de 1932 a 1957, esto es, casi 25 años cumplidos. Con la nueva Constitución Deus Scientiarum Dominus que inducía un cambio prófundo en los estudios eclesiásticos, se vino a fundar en la Universidad Gregoriana la nueva Facultad de Misionología, y para ese cometido era llamado a Roma el P. José Zameza, por orden expresa del General de la Orden, P. Ledochowski. Llevaba como cometido el echar los cimientos, y dar forma a la nueva Facultad, de la que quedaba nombrado su primer Decano. En la nueva Facultad explicó durante años, diversas disciplinas, como Introducción a la Misionología, Historia general de las Misiones, Patrística Misional, y algunos años también Teología fundamental y Ascética, en la Facultad de Teología. En la Facultad de Misionología fundó y dirigió la publicación studia Missionalia, órgano de la misma Facultad desde el 1942, donde pudieran ir publicándose los trabajos científicos de los Profesores, y aun de los alumnos más aventajados. Su estancia y sus ocupaciones de Roma, no le hicieron perder sus contactos con las Obras Misionales de España, donde, al menos en los veranos, multiplicaba sus intervenciones en Congresos y Semanas de Estudio sobre Misiones. $Y$ así siguió su labor hasta el 1 de Abril de 1957 en que falleció víctima de casi un

47. Publicada en Bérriz, en 1934, por la Editorial Angeles de las Misiones, con un total de 588 páginas. 
completo agotamiento. Dados estos breves datos biográficos, podemos pasar ya a la exposición de su teoria ${ }^{48}$.

La teoría misional del P. Zameza

Hemos expuesto ya parte de sus ideas con ocasión de la doctrina contenida en la Pastoral del Cardenal Benlloch. Ahora hemos de exponer sus ulteriores aportaciones a aquellas primeras y embrionarias ideas. Fueron apareciendo, aunque no con una determinada ligazón sistemática, en sus diversos artículos y obras. Quizás la principal de éstas sea, en este campo, su Amemus Ecclesiam, publicada en Burgos el año 1936, y ocho años más tarde en segunda edición publicada en Pamplona, con el título cambiado de Amemos a la Iglesia, prefiriendo ya un título español, lengua en que estaba escrita toda la obra. Es la edición que seguiremos en esta exposición.

Durante los años 1939, 1940 y 1941 fueron apareciendo en la prestigiosa revista misional italiana Il Pensiero Missionario, varios artículos en torno a las ideas misionales de San Agustín con los siguientes titulos: Il Totus Christus di S.Agostino nei suoi riflessi missionari, en el 1939; L'azione delle Missioni nel "Totus Christus" di San Agostino, en el 1940 y La realizzazione di "Totus Christus" di S. Agostino frutto dell'azione missionaria, en el $1941^{49}$. Estos artículos darian origen a su folleto, publicado en Burgos en español, en el año 1942, con el título de La Conversión del mundo infiel en la concepción de "Totus Christus" de San Agustín ${ }^{50}$.

La Encíclica de Pío XII sobre la doctrina del Cuerpo Místico, publicada en el 1943, venía a ser como una confirmación de las ideas del P. Zameza en el campo misional. En adelante esta doctrina tan espiritual, tan sublime y tan devota, entraría más de lleno en la vida y en la Teología de la Iglesia. Zameza no podía menos de apoyäse en ella y de comentar su doctrina. Lo hizo en diversos artículós que, con el título de Comentario misional a la Encíclica Mystici Corporis Christi, fue publicando en los meses de Febrero, Marzo y Abril de 1944 en la revista Catolicismo, y que quedaron recogidos en un folleto de 40 páginas editado en el 1945 con el título anterior, al que se anteponían las palabras Ecos de una Encíclica ${ }^{51}$.

48. Como bibliografía suya puede verse nuestra obra Una Misionología Española (Madrid 1959) 158-162.

49. Cf. Il Pensiero Missionario (1939) 193-208; (1940) 289-298; (1941) 3-8. $97 \mathrm{pp}$.

50. Publicado en Burgos en 1942, por el Seminario de Misiones Extranjeras;

51. J. ZAMEZA, Ecos de una Enciclica. Comentario misional de la Encícli- 
No paró ahí su producción sobre el tema. En 1951 apareció casi simultaneamente en "Misiones Extranjeras" de Burgos, y en el tomo-homenaje al P. Dindinger en ocasión de sus 70 años, el artículo El Cuerpo Místico de Cristo en Dogmática misionera en España desde el "Maximum Illud". Y por cierto, que no resalta lo suficiente en él su propia aportación, poniendo en cambio de relieve las otras aportaciones de los demás; por lo que nosotros ahora juzgamos oportuno el resaltarla.

Aún más, en el 1955 publicaba en la revista norteamericana Worldmission otro artículito, St. Augustine and the Infidel World: San Augustín y el mundo infiel ${ }^{52}$; y ese mismo año, en Bérriz, la tercera edición de una obrita sobre San Pablo, otro de sus grandes autores y maestros, con el título de $L a$ más sublime vocación misionera ${ }^{53}$. Pudiéramos decir que se hallaba en plena madurez de producción, pero prefirió el Señor llevárselo aquel 1 de Abril de 1957 para premiarle todos sus trabajos.

En todas estas obras y estudios van apareciendo las mismas ideas que ya antes había vertido en la Carta Pastoral del Cardenal Benlloch, y que eran las mismas que en sus clases iba exponiendo en la Universidad Gregoriana, como nosotros mismos tuvimos ocasión de oír. En una síntesis brevísima expone el mismo Zameza esa doctrina en su folleto La Conversión del Mundo infiel en la concención del Totus Christus de San, Agustín.

"A mi modo de ver, nos dice allí, la teología expansionista de San Agustín, en grandes rasgos comprende: primero una necesidad vital de expansión ad extra; y segundo, una función, también vital asimilativa ad intra; pero ambas obrando como propiedades de la Iglesia en cuanto ésta es Cuerpo Místico de Cristo. Esta necesidad de expansión relaciona la Iglesia externamente con los pueblos infieles en cuanto éstos todavía son tales. En virtud de ella, la Iglesia les debe proponer y ofrecer la Fe. En cambio, la función asimilativo-generadora se desdobla a su vez en dos actividades internas: una de incorporación y generación a la vez, por la que esas masas de infieles, persona a persona irán quedando asimiladas al Cuerpo Místico por la aceptación de la fe, sellada con el Bautismo; y otra de implantación, organización y consolidación, por la que esas mis-

ca Mystici Corporis Christi de Su Santidad Pio XII. Publicaciones de la Unión Misional del Clero. Madrid, 1945; $40 \mathrm{pp}$.

52. J. ZAMEZA, "St. Augustine and the Infidel World": Worldmission (1955) $70-79$.

53. Publicado en Bérriz el año 1955; 244 pp. 
mas masas, no ya como personas, sino como comunidades, quedarán orgánicamente establecidas y aseguradas según la naturaleza propia de la Iglesia.

Dentro de este cuadro, en la concepción agustiniana que tratamos de explicar, el punto de mira, 10 mismo de esa expansión ad extra, como de ésta asimilación ad intra del Cristianismo; no es sino la obra de la Catolicidad de la Iglesia, en cuanto ésta es Cuerpo Místico de Cristo. Lo demás son consecuencias o aplicaciones según se la considere en relación con los dos mundos existentes: el de la fe, o el de la infidelidad.

Es el mismo simil, de factura netamente agustiniana, que utilizó en 1622 Gregorio XV para dar una explicación apropiada de Ia labor misional, en su Bula fundacional de la Propaganda Fide; de manera que pudiéramos decir que la escuela española tiene también su arranque pontificio, enunciado en esa Bula. Dice así Gregorio XV: Se dijo a Pedro: Levántate, Pedro, mata y come (Se trata de la visión de Joppe), para prefigurar el oficio de Pedro y de sus sucesores, de congregar a los hombres (varia impietate insipientes), de las cuatro partes del mundo; a los que matándolos, esto es, despojándolos de su vida antigua, y así despojados, comiéndolos, esto es, convirtiéndolos en sus miembros de aquel Cuerpo, del que era El visible cabeza, los hiciera al mismo tiempo miembros de Cristo, cabeza invisible de la Iglesia, y así vinieran a participar de la generación de Cristo ${ }^{54}$.

Ciertamente, que en esta frase concisa y llena de sentido alegórico, en el orden físico, y podemos decir que también real en el orden de la gracia, se encuentran todos los elementos esenciales de su concepción misional. Explicando el pasaje mismo San Agustin dice textualmente: "Evidens mysterium. Discus est orbis terrarum: quatuor lineae discum continentes, quatuor orbis cardines...; animalia, omnes gentes...; esuriens Petrus, Ecclesia desiderans fidem gentium; coelestis, sanctum Evangelium: macta et manduca, occide quod sunt, fac quod est" ${ }^{55}$. Y en otro lugar: "Quid est mactare et manducare? Occidere in eis quod erant et in sua viscera assumere. Disuadisti pagano sacrilegia? Occidisti quod erat; dato Sacramento Christi incorporasti Ecclesiae? Manducasti" ${ }^{56}$.

Recordemos la escena misma que nos describen los Hechos de los Apóstoles: "Al día siguiente subió Pedro a la azotea a orar, cer-

54. Citado por J. Zameza en su obrita Totus Christus, 17.

55. Serm. 266, 6: PL 38, 1228.

56. Enarrationes in Ps. 103, 2: PL 37, 1359; 123, 5: PL 37, 1642. 
ca de la hora sexta. $Y$ vino a tener hambre, y quería tomar algo; pero mientras se lo preparaban, se obró en êl un éxtasis; y comtempló el cielo abierto y bajar una especie de vaso a manera de sábana grande, que cogido por las cuatro puntas era enviado sobre la tierra, en el cual había toda especie de cuadrúpedos y reptiles de la tierra y de volátiles del cielo. Y se oyó una voz: Levántate, Pedro, mata y come. Pedro dijo: De ningún modo, Señor, nunca jamás comí cosa profana ni inmunda. Y la voz contestó: No llames inmundo lo que Dios purificó. Y esto sucedió hasta tres veces, $y$ enseguida fue recogido el vaso en el Cielo" 57.

Esta es la narración, narrada por el autor sagrado sobre la citada visión. Nos dice a continuación que quedó Pedro reflexionando sobre su significado, $y$ en ese preciso momento llamaron a la puerta los dos enviados de Cornelio el Centurión, varón justo y temeroso de Dios, aunque gentil, el que preparaba Dios, con otra visión paralela, para su conversión, era la gentilidad que se ponía por primera vez en contacto con la Iglesia en la persona de su Representante y Vicario en este mundo. A esta luz es como hay que explicar la visión, y a esa luz la explica San Agustín, según las palabras que hemos citado.

"El misterio es evidente, nos dice; ese vaso o bandeja es el mundo; sus cuatro extremos son los cuatro puntos cardinales; los animales son los gentiles; el hambre de Pedro significa a la Iglesia deseando la fe de la gentilidad; la voz del Cielo es el Santo Evangelio; el mata y come es; mata lo que son y haz lo que tú eres. ¿Qué significa este matar y este comer? Matar en ellos lo que eran, y tomarlo dentro de sí. ¿Pudiste disuadir al pagano de sus sacrilegios?, entonces es cuando mataste 10 que era ¿Mediante el Sacramento de Cristo lo incorporaste a la Iglesia?, entonces es cuando lo comiste".

Hasta aquí San Agustin. Repetimos lo que decíamos antes: frases concisas, llenas de sentido alegórico en el orden físico, pero plenas de sentido real en el orden de la gracia, de la accesión del mundo gentil a la Iglesia de Cristo.

Quedan frente a frente la Iglesia y el Paganismo: dos realidades diametralmente opuestas, como las tinieblas y la luz, y que han de interferir en una conjunción maravillosa hasta convertirse en claridad de luz las lobregueces de las tinieblas: aquí se funden esas cuatro totalidades de que nos habla San Agustín: Cristo y su Iglesia, de la que es Cabeza en su Cuerpo Místico, y los infieles que han

57. Hech 10, 9-16. 
de ser asimilados e incorporados por medio de la Misión: Cristo, primer Misionero y enviado del Padre, que a su vez El mismo envia como cabeza responsable de su Cuerpo Místico, y que funda la Misión, toda Misión; su Iglesia, cuerpo en crecimiento ininterrumpido con sus leyes vitales de asimilación y de adaptación; el Paganismo, o los gentiles, materia que debe ser asimilada por este Cuerpo Místico; mediante la Misión, que es el medio de conjunción que unifica ambos elementos; cuatro totalidades reales y necesarias, explicación apropiada de San Agustín para este problema de la Misión; cuatro totalidades o plenitudes, que abarcan otras muchas más particularidades: plenitud de los tiempos, plenitud de los dos Testamentos, plenitud de los Angeles, plenitud del cielo y de la tierra, plenitud de misión, plenitud de razas, plenitud de Cristo en su Cabeza y en su Cuerpo; en un palabra, Totus Christus ${ }^{58}$.

Ahora cabe preguntar: ¿Qué función ejerce la Iglesia misionera y en qué consiste, según el concepto del Totus Christus, su admirable actuación en la conversión de los pueblos infleles? La respuesta es concorde con los principios biológicos de concebir el Cuerpo Místico, por San Agustín. El propio Espíritu Santo, como alma de este organismo divino, se encargará de dirigir toda su labor de captación, asimilación y desarrollo: es la función total expansiva de la Iglesia; en su labor especificamente misionera: primero, una necesidad imperiosa, vital, a extenderse fuera como una propago fidei, o propagación de la fe; es la virtud vitalmente propulsora del "Id por todo el mundo" y predicad la fe: la propagación de la fe ${ }^{\text {so }}$.

Luego, otra necesidad, también interna y vital, asimilatriz-regeneradora, con la que se verifica la intususcepción y regeneración misma espiritual de los pueblos. ¿Son pueblos sin fe, son todos género de animales como los que vio Pedro? Primer paso: Mata lo que son, que dejen su paganismo y se agreguen a la Iglesia. Pero en el Cuerpo de la Iglesia nadie entra - dice San Agustín-, si no muere primero. Muere lo que fue, para que sea lo que no fue ${ }^{60}$. Ingenioso retruécano del Santo, sistema tan propio suyo, que juega ingeniosamente con términos y conceptos.

Los hombres, para nuestra alimentación, para nuestra asimilación, no comemos los animales vivos; antes han de ser sacrificados y aderezados para ser comidos; la fórmula simbólica de la visión: Mata y come. Pedro (la Iglesia) debe aniquilar antes la parte

58. J. ZAMEZA, La Conversión del mundo infiel, 18-37.

59. J. ZAMEZA, La Conversión del mundio infiel, 48-49.

60. Enarrationes in Ps. 123, 5: PL 37, 1642. 
pagana de los pueblos con sus adherencias, y después comerlos, y así sólo quedará el que como alimento limpio se incorporen a la Iglesia, esto es, al Cuerpo del Señor ${ }^{61}$. Sólo así, como alimento limpio y puro puede ser incorporado a Cristo y a su Iglesia; viene un pagano, y aún palpita en él su idolatría; pero ha de ser injertado en los miembros de Cristo. Para ser injertado tiene antes que ser comido; pero la Iglesia no puede comerlo sin antes sacrificarlo; que renuncie a su mundo, y entonces es cuando es sacrificado; que crea en Dios, y entonces es cuando es comido. Es cuando queda transformado ya en Iglesia: Haz lo que eres. La fórmula completa: Mata lo que son y come (los paganos), para que sean lo que no son (Iglesia) ${ }^{62}$.

Función asimiladora que se une a otra función alegórica, que tiene mucho de real también: la función generadora, por la que atribuimos a la Iglesia una función: una generación maternal que nos hace pensar jubilosos en aquella concepción tan suave y filial de nuestra Santa Madre, la Iglesia Católica. También lo expone San Agustín: "Como Madre de todas las gentes que ofrece su regazo a Ios no regenerados (a los Paganos como los recibe en su seno virginal), y amamanta a los regenerados, como tesoro de la única herencia de Cristo que se extiende hasta los últimos términos de la tierra" 63.

Qué ideas tan fecundas de meditación y reflexión nos proporcionan estas concepciones de San Agustín. Así veía y explicaba él la función misionera de la Iglesia en aquellos tiempos en que no existían nuestras ideas modernas de misión, y que incluía él en esta rica teologia misional dentro de una Iglesia que estaba toda ella en estado de misión. Explicación teológica, y al mismo tiempo llena de suavidad y de espíritu, radicada en el dogma suavísimo en la Comunión de los Santos, por el que unos estamos siempre trabajando por el bien común y bienestàr de los demás.

La Iglesia es Madre, madre fecunda, que a todos nosotros sus hijos hace hermanos y herederos del Reino de Dios. Precisamente de esta maternidad mundial y fecundante le ha venido el que por razón de esta universalización haya merecido que se la llame, y sea, Católica ${ }^{64}$.

Pero no basta una inserción individual, aunque es necesaria, y

61. Serm. 149, 6: PL 38, 886.

62. J. ZAMEZA, La Conversión del mundo infiel, 49-50.

63. Ep. 22, 23, 4: PL 33, 96.

64. J. ZAMEZA, La Conversión del mundo infiel, 51. 
se requiere. La Iglesia misionera tiende a una acción orgánica colectiva; ésta supone ya la incorporación personal de los convertidos en el Cuerpo Místico de Cristo. Por eso Zameza no podía admitir la teoria de Charles que prescindía en el concepto de misión, de esta previa inserción personal. En su obra Amemos a la Iglesia lo rechaza expresamente:

"Confieso sinceramente, nos dice, que no estoy conforme con autores modernos de gran prestigio científico (Charles), que han escrito: "Notemos que el objeto específico de la actividad misionera no es, como se repite con demasiada frecuencia, el convertir a los paganos... Este fin es común a toda la actividad eclesiástica y cristiana; o más bien, como se diría en lenguaje filosófico, es el mismo genérico de todo apostolado". Mientras los grandes Papas misioneros, en sus célebres documentos oficiales sobre Misiones, y otros escritores dignos de nota, directa o indirectamente, no indiquen otra cosa (respetando opiniones que juzgamos muy autorizadas), a nadie debe extrañar que nosotros, en explicar la noción católica de misión, sigamos la triple y magnífica línea de la tradición, sin excluir del concepto de Misión a ninguna de las tres. Tal vez me equivoque, pero cuanto más estudio el asunto, me parece más delicado el desechar tan a rajatabla una parte tan importante de la concepción tradicional de la Misión" ${ }^{65}$.

Luego volveremos sobre esta triple línea de la tradición de que habla Zameza, y que no es más que la triple relación o connotación personal, orgánica y social de la Iglesia con respecto al objeto material de la misión.

No basta la incorporación personal; se necesita una labor de consolidación y permanencia colectiva, de organizaciones tiernas y recientes; como decía el Santo: Creen, son consagrados, exigen que sean ordenados clérigos para ellos ${ }^{66}$. Se trata ya de una Iglesia misionada en frase clara de formación orgánica: fe, sacramentos, sacerdocio. Tras la incorporación de las personas, y en éstas de las masas, el Cuerpo Místico de Cristo, se impone en cada región la constitución orgánica de las comunidades según la naturaleza jerárquica de la Iglesia; tras la aceptación de la fe por los pueblos, debe seguirse obviamente la organización de las Iglesias particulares. Sin ellas es difícil una duración connatural a la Iglesia, y se hace dificultosa la misma santificación de los fieles, último fin del Cristianismo en este mundo. Por eso el Apóstol iba fundando igle-

65. J. ZAMEZA, Amemos a la Iglesia, 132.

66. Enarrationes in Ps. 130, 4: PL 37, 1753. 
sias entre aquellas naciones a las que predicaba. Aquí tienen su raíz los términos utilizados por los Santos Padres al enjuiciar el apostolado misionero: fieri, pullulare; constitui, fundari, implantari, propagari Ecclesias: hacerse, pulular, constituirse, fundarse, implantarse, propagarse la Iglesia ${ }^{67}$.

Finalmente, queda el último estadio de la Misión: ¿Qué son todas estas Iglesias particulares, sino miembros organizados de la gran Iglesia, cuyo Sumo y Buen Pastor invisible es el mismo Cristo? Es la última función misionera, una función colectiva total, considerada, no ya en sus miembros como personas, ni en sus comunidades como Iglesias particulares, sino en toda su sublime unidad interna como "Cuerpo Místico" que es, de Jesucristo. Es El mismo el que se difunde, propaga, crece y fructifica por las Misiones; y como dice el Santo Obispo de Hipona, el que por todas partes se difunde... se dilata... se propaga... se extiende... fructifica... crece La concepción propia del Cuerpo Místico de Cristo, en plena actividad de asimilación, de crecimiento y de expansión ${ }^{68}$.

Para San Pablo, como para San Agustín, continúa Zameza ${ }^{69}$, la conversión de los gentiles, ella misma tiene en sí un significado sublime de oblación sagrada; diríamos que la Iglesia en todo el mundo de Misiones es una patena mundial o ara, en la que la Esposa de Cristo, por mano de sus misioneros, ofrece a su Divino Esposo la ofrenda sagrada de la santificación de nuevos pueblos y nuevas razas, logrando que incluso los mismos cuerpos de los paganos recién bautizados aparezcan a los ojos de Dios como hostia pura, hostia santa y hostia inmaculada.

Concluye Zameza que no conoce una concepción misionera más sublime respecto a lo que representa la obra misionera en relación con el Totus Christus del Santo Doctor ${ }^{70}$.

Todas estas profundas ideas misionales del Totus Christus son un complemento de las expuestas en la Pastoral de Benlloch del año 1920, y en Amemus Ecclesiam del 1936 y del $1944^{77}$.

Toda la función misional de la Iglesia, lo que podría llamarse su :misionalidad ad extra, es una única función misional con tres connotaciones, las tres esenciales, pero con términos connotados diversos. Son:

67. J. ZAMEZA, La Conversión del mundo infiel, 53-58.

68. J. ZAMEZA, La Conversión del mundo infiel, 58-59.

69. J. ZAMEZA, La Conversión del mundo infiel, 69.

70. J. ZAMEZA, La Conversión del mundo infiel, 69.

71. J. ZAMEZA, Amemos a la Iglesia, 127-154. 
a) Una connotación personal; ante todo tienen que "recibir la fe e'incorporarse a la Iglesia uno a uno los gentiles; nace, pues, la relación del derecho y de las obligaciones de la Iglesia para con estos infieles, que originan la connotación personal misionera: a eso se refieren las palabras de $\mathrm{N}$. Señor, de predicar el Evangelio a toda criatura; aunque es claro que no se necesita, para que la Iglesia quede establemente implantada en una región determinada, el que antes hayan recibido esta fe todos y cada uno de sus miembros componentes; únicamente se sigue que no se puede prescindir en la actividad misionera del trabajo de la conversión personal, pues en fin de cuentas la Iglesia se implantará a base de la conversión y santificación de los fieles.

b) Una connotación orgánica, pues la Iglesia es esencialmente orgánica en su naturaleza por institución divina; debe constar de comunidades e Iglesias, como la sociedad civil consta de familias; éstas unidas, y no los individuos precisamente, son las que constituyen el cuerpo de la sociedad; como tal, debe la Iglesia dilatarse entre los infieles, debe expansionarse conforme lo reclama esa exigencia orgánica; y ese derecho y necesidad de expandirse por todo el mundo, origina esencialmente la connotación orgánica misional.

c) Una connotación social; los misionados incorporados, y las comunidades organizadas ya, o en vías de organización aún, no tienen más razón de existir que ser, vivir, construir, actuar, y terminar formando todos una única Iglesia social; y esta última relación de que, conforme vayan bautizándose los infieles, y organizándose las nuevas cristiandades, se deba y tenga que ir extendiendo la Iglesia de Cristo, como única sociedad religiosa instituida por Cristo para atraer hacia sí todas las naciones, es lo que llamamos connotación social de la Iglesia misionera.

Como efecto de la primera, se predica la fe y se bautiza a los paganos como personas; como efecto de la segunda, se preparan, se organizan y perfeccionan gradualmente las Iglesias particulares misionadas hasta su connatural perfección jerárquica; y como efecto de la tercera, se extiende la misma Iglesia ex gentibus. Por eso, hablando los antiguos de lo que debía hacer la Iglesia al tratar de dilatarse entre la gentilidad, usaban, entre otros, estos tres términos: plantar la fe, plantar las Iglesias, plantar la Iglesia.

Los derechos y obligaciones de estas tres connotaciones, y lo mismo sus respectivos efectos de crecimiento, no sólo no se oponen entre sí, sino que se complementan; el aumento de nuevos cristia- 
nizados como miembros, de las nuevas comunidades con órganos, y de la Iglesia universal como Cuerpo de Cristo, en su fase de dilatación, integran lo que llamamos Iglesia misionera ${ }^{72}$.

Hemos resumido, lo más acertada y concisamente posible, las muchas ideas misionales que ha ido dejando caer el P. Zameza en sus obras y sus escritos. No dudamos en afirmar que tiene un sello de originalidad, y van bien avaladas por la doctrina del Apóstol de las Gentes y del Obispo de Hipona; y asi mismo que son tales, que pueden formar de por sí una verdadera escuela. Si queremos ver como en un cuadro toda esta doctrina expuesta del Cuerpo Místico en su connotación misional, podríamos hacerlo asi:

Misión: $\left\{\begin{array}{l}\text { concepto común: la común a todas las misiones de las } \\ \text { Religiones en general } \\ \text { concepto restringido: el propio de las Misiones Católicas }\end{array}\right.$

Su relación: $\left\{\begin{array}{r}\text { en su conversión y } \\ \text { como organización (connot. orgánica) a la plantación } \\ \text { en su bautismo } \\ \text { Dilatación del C.M. }\end{array}\right.$

Pero la Iglesia, como cuerpo vivo y orgánico-místico, actúa en una Doble ley $\left\{\begin{array}{l}\text { ley del desarrollo, como todo cuerpo vivo. } \\ \text { ley de la elasticidad adaptativo. }\end{array}\right.$ por la ley del desarrollo: $\left\{\begin{array}{l}\text { Se incorporan nuevos fieles adultos. } \\ \text { Crecen las Comunidades en evolución orgánica } \\ \text { Crece la Iglesia Universal de Cristo. } \\ \text { se extiende y regula por el Clero indígena }\end{array}\right.$ por la ley de la elasticidad: $\left\{\begin{array}{l}\text { se acomoda a pueblos, usos, lenguas, etc. } \\ \text { se acomoda a clases sociales... }\end{array}\right.$

De ahi que exista una relación estrecha entre Cristo y su Iglesia, a saber:

Cristo es la Cabeza de este Cuerpo Místico según la doctrina paulina.

La Iglesia es el cuerpo de esa Cabeza, pero Cuerpo Místico. Ambos extremos han de considerarse en sus diversas totalidades:

72. J. ZAMEZA, Amemos a la Iglesia, 133-134. 
Cristo como Cabeza: $\left\{\begin{array}{l}\text { como Persona divina es eterno } \\ \text { como Verbo Encarnado es medianero Totus } \\ \text { como Cabeza, preside al Cuerpo Místico Christus } \\ \text { la angélica, de suyo no entra en este Cuerpo. }\end{array}\right.$

Triunfante, ya en los cielos incorporada ya

Iglesia como Cuerpo: Ia Humana:

Peregrinante:

Tota Ecclesia

debe incorporarse aún

La Misión: $\left\{\begin{array}{l}\text { del Hijo por el Padre, como Redentor y Cabeza } \\ \text { del Espiritu Santo por Padre e Hijo, como alma de la } \\ \text { Iglesia por Cristo. } \\ \text { Son el objeto material de esa incorporación a Cristo. }\end{array}\right.$

Los gentiles $\left\{\begin{array}{l}\text { En un principio todos han de ser incorporados } \\ \text { algunos ya de hecho incorporados a Cristo. Totae Gentes } \\ \text { Luego los demás han de serlo, mediante las misiones }\end{array}\right.$

Se pregunta, ¿qué relación hay entre el Totus Christus (Cristo-Iglesia) y los gentiles?

La Iglesia es, como Cuerpo Místico de Cristo algo vivo, con fuerzas vitales propias:

ad extra: principio vital de expansión: $\left\{\begin{array}{l}\text { Catolicidad; Fecundidad... } \\ \text { Iglesia infieri; las Misiones }\end{array}\right.$

Elasticidad adaptativa en su apostolado al medio ambiente...

Función vital asimilativo-regeneradora: La Iglesia constituida ad intra:

Estas fuerzas vitales de la Iglesia, Cuerpo Místico.

Radican en su principio vital o alma, que es el Espiritu Santo.

Se manifiestan en estos cuatro estadios:

1) en la propagación de la fe (Propago fidei), ad extra, en virtud de la fuerza expansiva de la Catolicidad: Id, predicad; como me envió a Mí el Padre...

misión de Cristo: $\left\{\begin{array}{l}\text { personal a solos los Judios } \\ \text { por sus Apóstoles a todas las Gentes } \\ \text { por su Iglesia prolonga esa Misión a todas las } \\ \text { Naciones. }\end{array}\right.$ 
2) en la asimilación-regeneración (ad intra) de los infieles en Cuerpo de Cristo:

Asimilación: $\left\{\begin{array}{l}\text { Occide quod sunt et manduca (los Paganos) } \\ \text { Ut sint quod non juerunt (la Iglesia de Cristo). }\end{array}\right.$

Regeneración: $\left\{\begin{array}{l}\text { La Iglesia es nuestra Madre } \\ \text { como tal, engendra, alimenta e incolpora. }\end{array}\right.$

3) Llega a la madurez con una acción orgánica colectiva no basta la incorporación personal

es necesario la incorporación colectiva de la Iglesia

en su madurez, es ya la Iglesia totalmente constituida

4) Consecuencia: La Dilatación del Cuerpo Mistico de Cristo No se trata de Iglesias particulares, independientes entre sí. Todas ellas han de formar La Iglesia de Cristo.

Es Cristo el que va así dilatándose todo a lo largo y ancho de la tierra.

Según estas premișas, podríamos definir la Misión de la Iglesia misionera, como la actividad Misionera que consiste en la necesidad de actuar misioneramente; necesidad que le proviene de la misma Iglesia en cuanto es Cuerpo Místico y vivo actuando en una doble fuerza: de expansión ad extra (Catolicidad), a fin de obrar una asimilación ad intra. Por lo tanto, la acción misionera de la Iglesia es esencial a la misma Iglesia.

P. ANGEL SANTOS, S.J.

Universidad de Comillas

MADRID 
Bibliografía.

A. La Bibliografía sobre el aspecto misional y misionero de san Agustín es rica y abundante. Del Capuchino Walter podemos recordar su obra Die Heidenmission nach der L̇ehre des hl. Augustinus, Münster, 1921; VIIr, 216 pp.; ID.,"L'Idea Missionaria in S. Agostino"." Il Pensiero Missionario (1930)." 321346.

De la Semana Misional de Burgos de 1954, Contribución a una Misionología agustiniana. Burgos, 1955, podemos señalar los siguientes estudios:

CAPANAGA, V.: Algunos aspectos misionales: de la antropología agustiniana: 45-53.

ARMAS, G.: Las virtudes y la salvación de los infieles segün san Agustin 100110.

ZARRANZ, J. P.: Las luchas donatistas ofrecieron a san Agustin conyuntura magnifica para sentar las bases de su Teología misionera: 10-18.

FLOREZ, R.: Condiciones y sentido de la Teología misionera de san agustin: $26-37$.

PRADO, S. El tema misional en la predicación de san Agustín: 45-54.

ZAMEZA, J.: En la galería de grandes misionólogos. Autorretrato epistolar de san Agustin: 55-62.

RORIGUEZ, I.: El catecumenadio en la disciplina eclesiástica de san Agustin: 63-77.

RODRIGUEZ, I.: Bibliografía misional de san Agustín: 81-89, donde el autor recoge una gran cantidad de bibliografía sobre el Santo, aunque no específicamente de carácter misional, sino de aspecto general.

B. Otros autores.

CAPERAN, L.: La doctrine de Saint Augustine, en su obra Le Problème du salut des Infidèles, pp. 104-132.

COUTURIER, Ch.: "Les Saints païens selon saint Augustin": Spiritus (1963) $392-404$.

ERNST, J. Die Werke und Tugen der Unglaubigen nach Hl. Augustin. Freiburg, 1871.

GRASSO, D.: "Saint Augustin évangélisateur": Parole et Mission 22 (1963) 357378.

LAMIRANDE, E.: "S. Augustin: L'annonce de l'unité dans l'université": Spiritus 19 (1964) 157-174.

LAMIRANDE, E.: “Torrents de feu pour l'évangélisation du Monde. La transformation des Apôtres à la Pentecôte selon S. Augustin": Spiritus 23 (1965) $125-131$.

MARCOS, F.: "El Cristo místico y la Comunión de los Santos según san Agustín": Religión y Cultura (1931) 402-460.

EMETZGER, G.: Kirche und Mission in den Briefen Augustinus. Güterloh, 1936. RIEDL, J. von: "Röm 2, 14 ss. und das Heil der Heiden bei Augustinus und Thomas": Scholastik (1965) 189-214.

ROMENS, C.: Das Heil des Christen ausserhalb der wahre Kirche nach der Lehre des Hl. Augustin. Paderborn, 1908.

SAINZ MAZPULE, J.: "El pensamiento misionero de san Agustín": Catolicismo (Agosto, 1942) 6-7.

SPINTZENBERG, D.: "Augustinus und die Heidenmission": St. Augustin (1930) 117-121. 
VOOGHT, P.: "Saint Augustin et les vertus des païens": Bulletin des Missions (1938) 193-196.

WANG TCHANG TCHE: Saint Augustin et les vertus païens. Paris, 1938.

ZAMEZA, J.: Amemus Ecclesiam. Instrucciones patristico-misionales para sacerdotes. Burgos, 1936. Las 416 páginas se centran, principalmente, en torno a las ideas de san Agustín. Con una segunda edición, con título castellano Amemos a la Iglesia fue publicada en San Sebastián el año 1944; 415 pp.

ZAMEZA, J.: La Conversión del mundo infiel en la concepción del "Totus Christus" de san Agustin. Burgos, 1942.

ZAMEZA, J.: Ráfagas de luz agustiniana. Bérriz, 1955.

ZAMEZA, J.: "San Agustín y los grandes problemas misionales": El Siglo de las Misiones (1930) 233-242.

ZAMEZA, J.: "Il "Totus Christus" di S. Agostino nei suoi riflessi missionari": Il Pensiero Missionario (1940) 193-208.

ZAMEZA, J.: "Ai piedi della Croce. Prospettive agostiniane": Il Pensiero Missionario (1939) 11-18.

ZAMEZA, J.: "L'azione delle Missioni nel "Totus Christus" di Saint'Agostino": Il Pensiero Missionario (1940) 289-298.

ZAMEZA, J.: "La realizzazione del "Totus Christus" di S. Agostino, frutto dell'azione missionario": Il Pensiero Missionario (1940) 3-8.

ZAMEZA, J.: "St. Augustin and the Infidel world": Worldmission (1955) 70-79. 